\title{
Commentary: Understanding limitations
}

\author{
Daniel P. Raymond, MD
}

I propose a change in the format of scientific publications. The limitations are routinely hidden in the second to last paragraph of the discussion, with the hope that most readers have already fatigued to the point that they jump to the flamboyant conclusion statement. Understanding the limitations are, however, essential to interpreting the data. Thus I suggest that the limitations should be placed after the methods and before the results, so that readers are aware of them while formulating their opinion of the results.

Such understanding is essential for the interpretation of the study by Hennon and colleagues, ${ }^{1}$ which examines the relationship between short- and long-term outcomes in a lung cancer population. Onaitis and colleagues ${ }^{2}$ established a long-term survival model for patients older than age 65 years who have undergone surgical therapy for lung cancer. Hennon and colleagues ${ }^{1}$ expand on it by including nonsurgical lung cancer therapy, thus providing a broader look at center-associated care and conclude that there is a poor correlation between 30-day surgical outcomes and long-term outcomes. Interpreting these results requires an understanding of the limitations of the study which are primarily due to the data source, which is the National Cancer Database (NCDB). A primary limitation of this database is the lack of availability of cancer-specific outcome, specifically disease-free survival. Rather, we depend on crude survival, which is highly problematic in an elderly, smoking population where significant comorbid processes such as cardiovascular disease, lung disease, and metachronous cancers will contribute to mortality. In the NCDB, this potential confounder is managed by the Charlson comorbidity index (CCI), which has been shown to a be a poor indicator

\footnotetext{
From the Department of Thoracic and Cardiovascular Surgery, Cleveland Clinic, Cleveland, Ohio.

Disclosures: The author reported no conflicts of interest.

The Journal policy requires editors and reviewers to disclose conflicts of interest and to decline handling or reviewing manuscripts for which they may have a conflict of interest. The editors and reviewers of this article have no conflicts of interest.

Received for publication Dec 3, 2020; revisions received Dec 3, 2020; accepted for publication Dec 3, 2020; available ahead of print Dec 17, 2020.

Address for reprints: Daniel P. Raymond, MD, Department of Thoracic and Cardiovascular Surgery, Cleveland Clinic, 9500 Euclid Ave, J4-1, Cleveland, OH 44195 (E-mail: Raymond3@ccf.org).

J Thorac Cardiovasc Surg 2022;163:274-5

0022-5223/\$36.00

Copyright (c) 2020 by The American Association for Thoracic Surgery

https://doi.org/10.1016/j.jtcvs.2020.12.037
}

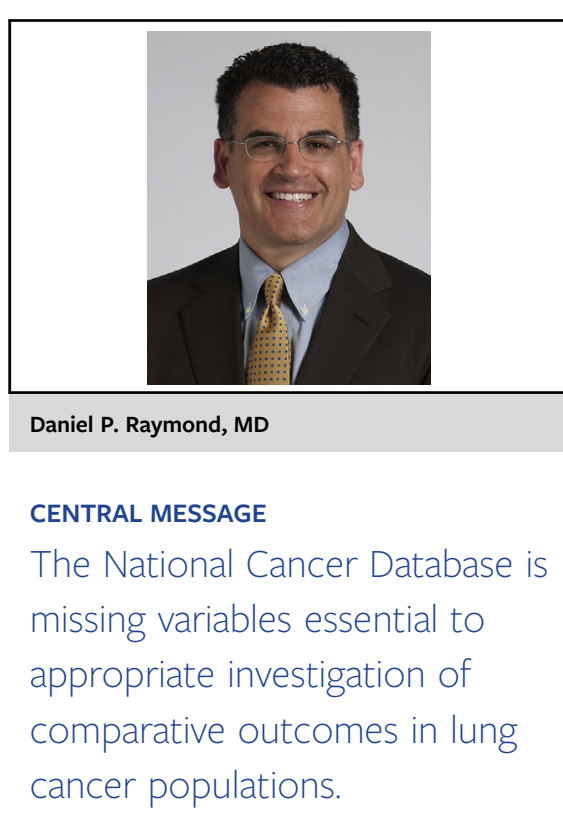

of survival in lung cancer populations. ${ }^{3-5}$ This is not surprising when one scrutinizes the components of the CCI. The only indicator of lung health is the presence or absence of diagnosed chronic obstructive pulmonary disease. The Society of Thoracic Surgeons General Thoracic Surgery Database has dropped the term chronic obstructive pulmonary disease in its comorbidity analysis due to the inappropriate use of a loosely defined term that is rampant in the medical community. Moreover, the CCI lacks statistically significant indicators of long-term outcome in a lung cancer population identified by Onaitis and colleagues, ${ }^{2}$ including body mass index, smoking status, chronic steroid use, forced expiratory volume in $1 \mathrm{sec}-$ ond (FEV1), and reoperative surgery. The NCDB and CCI, as a result, do not differentiate between a morbidly obese, home oxygen- or steroid-dependent smoker with an FEV1 $<40 \%$ and a former smoker who quit 20 years prior with an FEV1 $>80 \%$ and exercises daily. Clearly, this lack of ability to appropriately risk-stratify significantly influences the extent to which NCDB data can be used to investigate comparative outcomes in lung cancer populations.

Of further concern is the attribution of long-term, crude survival to the cancer center providing the cancer care for the patient. A review of the patient distribution coming to my home institution reveals that more than $50 \%$ of patients come from outside a 7-county area surrounding Cleveland. This suggests a large portion of patients are obtaining their chronic health management and portions of their oncology care outside of the cancer center to which the outcome is 
being assigned. Suggesting that such a metric should be used to compare institutional performance is faulty without further granularity in the data.

I laud the authors on a fine statistical analysis and article; unfortunately, they started with a data set with substantial limitations when it comes to evaluation of lung cancer patient outcomes, thus compromising their conclusions. The authors have asked a very relevant question that warrants further investigation. I am very concerned that most thoracic surgeons are unaware of the substantial limitations present in the NCDB and other large databases and that, combined with a propensity to simply skip over the well-hidden limitations paragraph presented in articles, prevents readers from truly understanding the fallibilities of such analyses.

\section{References}

1. Hennon M, Groman A, Kumar A, Castaldo L, George S, Demmy T, et al Correlation between perioperative outcomes and long-term survival for non-small lung cancer treated at major centers. J Thorac Cardiovasc Surg. 2022;163:265-73.

2. Onaitis MW, Furnary AP, Kosinski AS, Kim S, Boffa D, Tong BC, et al. Prediction of long-term survival after lung cancer surgery for elderly patients in the Society of Thoracic Surgeons General Thoracic Surgery database. Ann Thor Surg. 2018;105: 309-16.

3. Siegneurin A, Delafosse P, Tretarre B, Woronoff AS, Velten M, Grosclaude P, et al. Are comorbidities associated with long-term survival of lung cancer? A population-based cohort study from French cancer registries. BMC Cancer. 2018;18:1091.

4. Sandfeld-Paulsen B, Meldgaard P, Aggerholm-Pedersen N. Comorbidity in lung cancer: a prospective cohort study of self-reported versus register-based comorbidity. J Thorac Oncol. 2017;13:54-62.

5. Tammemagi CM, Neslund-Dudas C, Simoff M, Kvale P. Impact of comorbidity on lung cancer survival. Int J Cancer. 2003;103:792-802.
See Article page 265

\section{Commentary: Waiting is among the great arts $($ or rather, why oncologic programs should be rated on long-term outcomes)}

\author{
Marco Scarci, MD, FRCS (Eng), FCCP, FACS, \\ FEBTS, and Federico Raveglia, MD
}

The article by Hennon and colleagues ${ }^{1}$ piqued our interest because the authors adressed a topic with several meaningful implications for both patients and health care providers. Assuming that established criteria for ranking cancer centers are based on short-term outcomes, they seek to understand if those correlate with long-term outcomes. Indeed, long-term results better depict the likelihood of being cured

\footnotetext{
From the Department of Thoracic Surgery, ASST Monza e Brianza, Ospedale San Gerardo, Monza, Italy.

Disclosures: The authors reported no conflicts of interest.

The Journal policy requires editors and reviewers to disclose conflicts of interest and to decline handling or reviewing manuscripts for which they may have a conflict of interest. The editors and reviewers of this article have no conflicts of interest.

Received for publication Nov 23, 2020; revisions received Nov 23, 2020; accepted for publication Nov 24, 2020; available ahead of print Dec 4, 2020.

Address for reprints: Marco Scarci, MD, FRCS (Eng), FCCP, FACS, FEBTS, Department of Thoracic Surgery, ASST Monza, Via Pergolesi 33, Monza, Italy (E-mail: marco.scarci@mac.com).

J Thorac Cardiovasc Surg 2022;163:275-6

$0022-5223 / \$ 36.00$

Copyright (C) 2020 by The American Association for Thoracic Surgery

https://doi.org/10.1016/j.jtcvs.2020.11.136
}

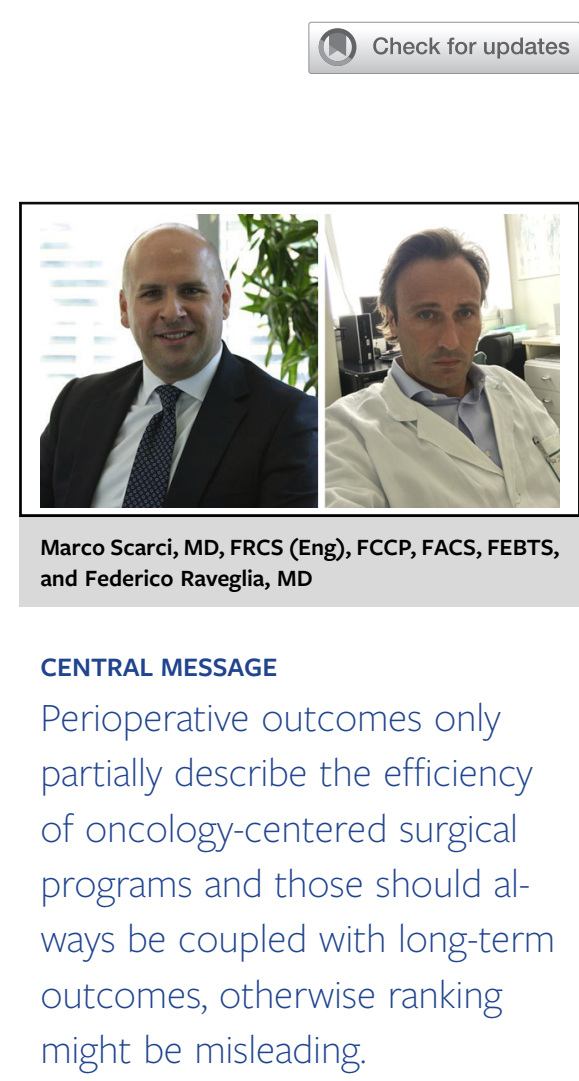

by cancer, rather than just surviving surgery. With modern advances in perioperative management and minimally invasive surgery, risk of death is significantly lower than in the past, so metrics should reflect more quality of life and avoid recurrences. Shifting the focus from short-term to long-term outcomes is a milestone because it affects the criteria used both by patients to select cancer centers and also by hospital administrators to obtain a better rating. Remarkably, by 